\title{
Canada not immune to spread of polio
}

$\mathrm{T}$

he current international spread of polio poses a risk of an outbreak in Canada, according to a WHO advisor on immunization, vaccine and biologics. Dr. Noni MacDonald says several vulnerable points in Canada's immunization approach and coverage could align to lead to infections.

Polio is making headlines with increased cases in seven endemic countries and cross-border spread to three additional countries. WHO declared the spread of polio in Africa and the Middle East an international emergency in May.

Canada has had few polio cases since widespread vaccination in the 1950s and 1960s, with the last recorded case of wild poliovirus infection in 1977. Canada uses the inactivated poliovirus vaccine, which prevents disease, rather than the oral live attenuated-virus vaccine, which also prevents carriage. This means most Canadians are protected from getting the disease, but can circulate the virus because they lack gut immunity, says MacDonald, an expert in pediatric infectious diseases.

The danger in Canada is a silent spread to pockets of the population that are not immunized, she says. "We have populations with low to no polio vaccine uptake.... And we have populations where rates of polio uptake are not in the $80 \%$ range needed for herd protection, so we are at risk."

The rates of polio vaccination are difficult to ascertain; some provinces track rates, but others do not. The Public Health Agency of Canada's national immunization coverage surveys involve relatively small samples of only several thousand, says MacDonald.

The latest survey, in 2011, showed polio immunization rates well above $90 \%$ by seven years of age, but surveys in previous years showed rates of only $80 \%$. Further, many adults lack sufficient immunity, and would need boosters in case of an outbreak, says MacDonald.

It would also be difficult to detect cases in the event of a Canadian outbreak. Usually, only about $1 \%$ of infections results in clinical disease. In recent outbreaks in Tajikistan — previously poliofree - and Syria, hundreds were infected before clinical cases were identified.

"We would not detect it in Canada

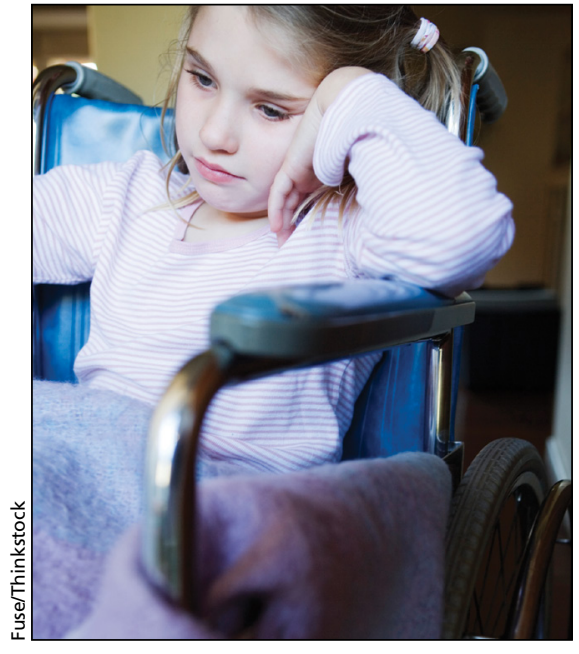

The danger in Canada is the silent spread of polio among those who are not immunized.

until we had a case of clinical polio," says MacDonald.

What should Canada do to protect the population? MacDonald says "the best solution is to eliminate polio [globally], as humans are the only host. That means increased immunization in countries where it is still endemic."

The solution in endemic countries is "community engagement, additional strategies for routine immunizations, a whole range of things," says Dr. Zulfiqar Bhutta, the Robert Harding Inaugural Chair in Global Child Health at The Hospital for Sick Children, Toronto "The answer is not to put a Berlin Wall around these countries."

He thinks that Canada should not restrict entry of travellers from these countries. "I don't think that would work. It would be scare-mongering."

Bhutta and MacDonald agree that the current emergency results from strife. "It is very difficult to control the disease in the middle of a conflict. We are seeing reintroductions in Syria and Somalia where the health system has broken down," says Bhutta.

Adds MacDonald, "Polio thrives where there is disruption in access to health care and hence immunization on time because of conflicts, local community obstruction or benign neglect of immunization programs." - Carolyn Brown, Ottawa, Ont.

CMAJ 2014. DOI:10.1503/cmaj.109-4812 